\title{
Follicular, endocrine and behavioural dynamics of the Indian rhinoceros (Rhinoceros unicornis) oestrous cycle
}

\author{
Monica A Stoops, Randal D Pairan and Terri L Roth \\ Center for Conservation and Research of Endangered Wildlife, Cincinnati Zoo and Botanical Garden, Cincinnati, \\ Ohio 45220, USA
}

Correspondence should be addressed to M A Stoops; Email: monica.stoops@cincinnatizoo.org

\begin{abstract}
Longitudinal ultrasound, behaviour and endocrine evaluations were conducted, over 14 to 18 months, in two young female Indian rhinoceroses (Rhinoceros unicornis) to characterize the oestrous cycle. Both females showed the same pattern of follicular development producing a large follicle $(10-12 \mathrm{~cm}$ diameter) on one of the ovaries that persisted for $8.5 \pm 4.68$ days before spontaneously ovulating. Ovulation occurred in all eight cycles monitored in a 6- to 7-year-old female versus 10 out of 14 cycles monitored in a 5- to 6-year-old female. Ultrasound examinations confirmed follicular collapse $48 \mathrm{~h}$ following the onset of behavioural oestrus in ovulatory cycles, while anovulatory cycles were associated with the formation of a haemorrhagic follicle. The day of behavioural oestrus corresponded to peak urinary oestrogen conjugate concentrations for each cycle, but anovulatory cycles had lower concentrations on the day of behavioural oestrus compared with ovulatory cycles. A transient increase in urinary progesterone metabolite concentrations was detected 1 day prior to ovulation. Irregular urinary progesterone metabolite profiles followed anovulatory cycles, reflecting varying degrees of follicular luteinization. In an attempt to ensure that a cycle would result in ovulation in the 5- to 6-year-old female, a GnRH treatment was tested during two separate cycles. Administration of $\mathrm{GnRH}$ on the day of behavioural oestrus resulted in an increase in urinary luteinizing hormone concentrations $\mathbf{2} \mathrm{h}$ following injection. Regardless, ovulation did not occur in response to treatment. This study provides the first ultrasound data on ovarian activity in the Indian rhinoceros and establishes normal physiologic and behavioural relationships during the oestrous cycle that may facilitate the breeding of this species in captivity.

Reproduction (2004) 128 843-856
\end{abstract}

\section{Introduction}

The Indian rhinoceros (Rhinoceros unicornis) is the largest of the Asiatic rhinoceros species. Once ranging throughout most of Southeast Asia, wild populations of Indian rhinoceros are now found in two protected areas, southern Nepal and Assam, India. Wild population estimates for the Indian rhinoceros currently range from 2000 to 2100 animals (Foose \& Van Strien 1997, Dinerstein 2003) with the captive population consisting of 138 animals distributed in 52 zoological institutions throughout North America, Europe, Asia and Australia (Hlavacek et al. 2002). Although captive breeding of the Indian rhinoceros has been rather successful in terms of the number of offspring produced, genetic representation is significantly skewed towards a few highly prolific founders (Zschokke et al. 1998, Hlavacek et al. 2002). In order to guarantee maximal genetic variation in subsequent generations of captive Indian rhinoceroses, breeding and successful reproduction must occur with regularity between specifically paired males and females.
Natural breeding attempts among captive Asian rhinoceros species frequently result in severe aggression between males and females (Khan et al. 1999, Roth \& Brown 1999, Roth et al. 2001). Unlike the Sumatran rhinoceros (Dicerorhinus sumatrensis), the Indian rhinoceros typically exhibits overt signs of oestrous behaviour that traditionally have been used to time introductions for mating. Even so, many male Indian rhinoceroses have not sired offspring because they expressed significant aggression when introduced to a behaviourally oestrual female (Roth \& Brown 1999). The ability to characterize ovarian, endocrine and behavioural dynamics associated with the periovulatory period in the Indian rhinoceros could greatly assist in timing introductions for mating and for developing assisted reproductive techniques, such as artificial insemination (Al), to help improve the genetic diversity of this species in captivity.

To optimize the likelihood of conception following natural breeding or $\mathrm{Al}$, ovulation must occur near the time of insemination. Therefore, the timing of breeding or Al relies heavily on an understanding of female reproductive 
physiology, yet reproductive data on most exotic animals are still very limited. However, recent advances in understanding female reproductive physiology in the Sumatran, African black (Diceros bicornis) and African white (Ceratotherium simum) rhinoceroses have expanded the knowledge base while revealing substantial variation in reproductive function among the rhinoceros species (Schwarzenberger et al. 1993, 1998, Berkeley et al. 1997, Radcliffe 1997, 2001, Roth et al. 2001, 2004, Patton et al. 1999, Roth \& Brown 1999). Several of these studies utilized a combination of sera, faecal and/or urinary hormone analysis and rectal ultrasonography to delineate oestrous cycle dynamics, thereby producing information directly applicable to captive breeding efforts. For example, longitudinal analysis of serum progesterone concentrations and ultrasound imaging of ovarian and uterine tissue led to our understanding of Sumatran rhinoceros reproductive physiology and resulted in the first successful breeding of a captive Sumatran rhinoceros in 112 years (Roth et al. 2001, 2004). Similar information regarding the reproductive biology of the Indian rhinoceros is limited.

Both urinary and faecal hormone metabolite data matched to observations of behavioural oestrus have been used to monitor reproductive cyclicity in the Indian rhinoceros (Kassam \& Lasley 1981, Kasman et al. 1986, Hodges \& Green 1989, Schwarzenberger et al. 2000). These studies documented significant variability in the duration of the ovarian cycle, ranging from 39 to 64 days (Kassam \& Lasley 1981, Kasman et al. 1986, Schwarzenberger et al. 2000). However, none of these studies incorporated ultrasonography in the methodologies employed. Therefore, detailed data on follicular dynamics, growth and ovulation do not exist. It was primarily through ultrasound monitoring that another Asiatic species, the Sumatran rhinoceros, was discovered to be an induced ovulator that exhibits a 21-day reproductive cycle when allowed to mate (Roth et al. 2001). In contrast, spontaneous ovulation has been documented by ultrasonography in both African black and African white rhinoceroses, with mean cycle lengths of 26 and 33 days respectively (Radcliffe et al. 1997, 2001).

The overall aim of this study was to characterize the Indian rhinoceros oestrous cycle and to establish the physiologic events associated with the periovulatory period that may help to improve captive breeding and AI success. Specific objectives were (1) to characterize ovarian activity by rectal ultrasonography; (2) to monitor behavioural oestrus in relation to ovulation; (3) to correlate urinary oestrogen conjugate $\left(\mathrm{E}_{1} \mathrm{C}\right)$ and progesterone metabolite (PdG) concentrations excreted during the oestrous cycle to ovarian and behavioural dynamics; (4) to validate the use of a luteinizing hormone $(\mathrm{LH})$ enzyme immunoassay (EIA) for measuring urinary $\mathrm{LH}$; and (5) to determine if gonadotrophin releasing hormone $(\mathrm{GnRH})$ administration during the periovulatory period would induce ovulation at a predictable time post-injection.

\section{Materials and Methods}

\section{Animals}

This research was conducted on two female Indian rhinoceroses maintained at the Cincinnati Zoo and Botanical Garden, Cincinnati, OH, USA. The females were maintained at the institution during separate time periods and are therefore presented as independent studies. Both females were captive born. The females had access to an outdoor exhibit $(27 \times 32 \mathrm{~m})$ when weather allowed (temperature $\left.>7.2^{\circ} \mathrm{C}\right)$ and had access to a pool $(9 \times 9 \mathrm{~m})$ in their exhibit when the temperature was $>15.6^{\circ} \mathrm{C}$. The exhibit for the female Indian rhinoceros was adjacent to the exhibit for the male Indian rhinoceros. The same male Indian rhinoceros (Studbook (SB) no. 147) was maintained at the institution throughout both studies. While housed inside, the female had access to 2 stalls (each $5 \times 6 \mathrm{~m}$ ) that were separated from the stall for the male Indian rhinoceros by a $6 \mathrm{~m}$ distance that contained the chute for conducting the ultrasound examinations and an empty pass-through used to shift the animals. The animals were exposed to artificial lighting in the indoor facility and, depending on the season, the facility was heated or cooled. Each day the female Indian rhinoceros was fed 1 bale of Timothy hay, 12 quarts of grain (ADF16; Mazuri, St Louis, MO, USA), 6 bananas, 6 carrots, 6 apples and 2 sweet potatoes. Each morning the female received $6 \mathrm{ml}$ vitamin E supplement (Emcelle Tocopherol; 500 i.u. $/ \mathrm{ml}$; Stuart Products Inc., Bedford, TX, USA) orally in a banana. In addition, the female was granted unlimited access to a mineral block and water. Fresh browse was offered opportunistically depending on the season.

\section{Study no. 1}

Indian rhinoceros (SB no. 189) 'Nikki' was born at the Toronto Zoo on 25 December 1991 and was 6 to 7 years of age during the study (8/5/98 to $8 / 7 / 99)$.

\section{Study no. 2}

Indian rhinoceros (SB no. 238) 'Chitwan' was born at the Smithsonian National Zoological Park on 18 September 1996 and was 5 to 6 years of age during the study $(1 / 11 / 01$ to $28 / 5 / 03)$. In January 2003 , the artificial lights in the stalls housing the female were set to a fixed $14 \mathrm{~h}$ exposure regimen each day (0600 to $2000 \mathrm{~h}$ ).

\section{Rectal ultrasonography}

The restraining device used during rectal ultrasonography was a steel constructed chute large enough to accommodate the entire animal. The animals entered and exited the chute through horizontally sliding concrete doors located at each end. The front door was closed as the female entered, with a hydraulic steel V-shaped designed back gate which closed after the female was in the chute. In addition, one entire side of the chute could move laterally 
to decrease the amount of lateral movement the female could achieve during the examination. The female was in the chute for 10-15 min for each examination. She was provided with feed as part of the conditioning process. An Aloka 500 machine (Aloka, Wallingford, CT, USA) connected to a $\mathrm{Hi}-8$ video or $\mathrm{CD}$ recorder and a $5 \mathrm{MHz}$ linear array probe were used for all examinations. A Sony thermal printer (Aloka) was used to print the images from the $\mathrm{Hi}-8$ video recorder, while Terapin Video Editing Software (Total Machine Vet Services, Orient, OH, USA) was used to capture images as jpeg files from the $C D$. Because the left ovary was anatomically located beyond the reach of the palpator, use of an extension attached to the probe was required to view the entire left uterine horn and ovary. The start of ultrasound examinations denoted day 1 of each study. During the examination, the bladder, cervix, uterine body, uterine horns and both ovaries were examined. Ovarian follicles $>1 \mathrm{~cm}$ in diameter were measured and the presence of luteal tissue was recorded. Each female was examined 3 to 7 times each week. Day 0 of an oestrous cycle was defined as the day ovulation was confirmed by ultrasonographic visualization of follicular collapse followed by the formation of a luteal structure.

\section{Study no. 1}

Ultrasound examinations were conducted on female no. 189 from day 1 to day 438 (8/5/98 to $8 / 7 / 99)$ with the exception of days 193 to 257 (30/11/98 to 2/2/99).

\section{Study no. 2}

Ultrasound examinations were conducted on female no. 238 from day 1 to day 575 (1/11/01 to 28/5/03). When follicle size reached $>10 \mathrm{~cm}$ in diameter, daily examinations were performed. With the onset of behavioural oestrus, ultrasound examinations were performed at $12,24,36,48$ and $72 \mathrm{~h}$ post-oestrus to correlate timing of ovulation in relation to behavioural oestrus. During behavioural oestrus, the female did not show interest in feed while in the chute, so fresh male Indian rhinoceros faeces was used to hold her attention while the ultrasound procedure was performed.

\section{Collection of urine samples}

Keeper staff obtained fresh urine samples by aspiration off the stall floor or collecting directly into a storage vial when the female urinated with her body oriented to facilitate mid-stream collection.

\section{Study no. 1}

Fresh urine samples were opportunistically collected from day -14 to day 435 . All urine samples were frozen $\left(-20^{\circ} \mathrm{C}\right)$ immediately following collection in $5 \mathrm{ml}$ round bottom polypropylene tubes (Corning Incorporated, Corning, NY, USA) and subsequently assayed for $\mathrm{E}_{1} \mathrm{C}$ and $\mathrm{PdG}$ concentrations.

\section{Study no. 2}

Fresh urine samples were collected opportunistically from day -87 to day 575 . An aliquot of urine $(1 \mathrm{ml})$ was kept at refrigerator temperature in a $1.5 \mathrm{ml}$ Eppendorf tube for subsequent $\mathrm{LH}$ analysis, while the remaining volume of urine was frozen $\left(-20^{\circ} \mathrm{C}\right)$ in a $5 \mathrm{ml}$ polypropylene round bottom tube and later assayed for $\mathrm{E}_{1} \mathrm{C}$ and $\mathrm{PdG}$ concentrations.

\section{Enzyme immunoassays}

\section{Studies 1 and 2}

Concentrations of urinary $E_{1} C$ and $P d G$ were measured using EIA techniques described by Munro et al. (1991). Polyclonal antibodies R522 and R13904 (supplied by C Munro, University of California, Davis, CA, USA) were utilized in the $\mathrm{E}_{1} \mathrm{C}$ and $\mathrm{PdG}$ EIAs respectively. Standard concentrations for both assays were 3.9 to $250 \mathrm{pg} \mathrm{well}^{-1}$. The $\mathrm{E}_{1} \mathrm{C}$ and $\mathrm{PdG}$ EIAs were validated for Indian rhinoceros urine by demonstrating parallelism between standard curves and serial dilutions of pooled urine (neat to 1:640). Frozen-thawed urine samples were run at a 1:80 dilution in EIA buffer for both assays. Interassay coefficients of variation for the $E_{1} C$ assay were $19 \%$ and $20 \%$ for internal controls at $38 \%$ and $83 \%$ binding respectively. Interassay coefficients of variation for the PdG assay were $19 \%$ and $13 \%$ for internal controls at $42 \%$ and $86 \%$ binding respectively. Creatinine concentrations were measured using a commercially available kit (no. 558-A; Sigma Diagnostics, St Louis, MO, USA). Urine samples were diluted 1:10 in double-distilled water $\left(\mathrm{H}_{2} \mathrm{O}\right)$ for the creatinine assay. Urinary concentrations of steroid hormones were indexed by creatinine concentration in the urine and expressed as $\mathrm{ng} \mathrm{mg}^{-1}$ creatinine $(\mathrm{Cr})$.

\section{Study no. 2}

Concentrations of LH in Indian rhinoceros urine samples were measured using an ElA originally developed to detect LH in elephant sera (Graham et al. 2002). Microtiter plates (96-well Maxisorp Nunc Immunoplates; Nalge Nunc International, Rochester, NY, USA) were coated with $50 \mu \mathrm{l}$ monoclonal mouse anti-bovine $\mathrm{LH} \beta$ antibody (Quidel clone no. 518-B7; supplied by J Roser, University of California, Davis, CA, USA) at a 1:15000 dilution in coating buffer, covered with an acetate plate sealer and placed at room temperature for a minimum of $12 \mathrm{~h}$. Following incubation, all wells of the microtiter plate were washed 5 times with wash solution and blotted dry. LH assay buffer was added to the plate $\left(50 \mu \mathrm{l}\right.$ well $\left.^{-1}\right)$ and equilibrated at room temperature for $30 \mathrm{~min}$. Following equilibration, $50 \mu \mathrm{l} \mathrm{NIH-bovine} \mathrm{LH} \mathrm{standards} \mathrm{(A} \mathrm{F} \mathrm{Parlow;}$ NIDDK, National Hormone and Pituitary Program, Torrance, CA, USA) and Indian rhinoceros urine samples were added to the plate in duplicate. Plates were sealed and incubated overnight at room temperature. After overnight incubation, $50 \mu \mathrm{l}$ biotinylated $\mathrm{NIH}$-ovine $\mathrm{LH}$ 
(A F Parlow, NIDDK National Hormone and Pituitary Program) were added to each well at a 1:8000 dilution in $\mathrm{LH}$ assay buffer and allowed to compete for $3 \mathrm{~h}$ at room temperature. Plates were washed 5 times, blotted dry and $100 \mu \mathrm{l}$ streptavidin-peroxidase conjugate (Roche Molecular Biochemicals, Indianapolis, IN, USA) at a 1:16000 dilution in LH assay buffer were added to each well. Plates were again washed 5 times, blotted dry and $200 \mu \mathrm{l}$ LH substrate solution $(24 \mathrm{ml} \mathrm{LH}$ substrate buffer, $100 \mu \mathrm{l}$ $0.1752 \mathrm{M} \mathrm{H}_{2} \mathrm{O}_{2}$ and $0.5 \mathrm{ml} 0.016 \mathrm{M}$ tetramethylbenzidine in dimethylsulphoxide) were added to all wells. Plates were allowed to develop for $1 \mathrm{~h}$ at room temperature before stopping the reaction with $50 \mu \mathrm{l}$ well ${ }^{-1}$ of $4 \mathrm{M}$ sulphuric acid.

Standard concentrations were 3.9 to $250 \mathrm{pg}$ well ${ }^{-1}$. A dose-response analysis of pooled unfrozen urine samples collected from female no. 238 following GnRH treatment no. 1 was used to demonstrate parallelism to the standard curve. Interassay coefficients of variation for the $\mathrm{LH}$ assay were $18 \%$ for internal controls at $20 \%$ and $88 \%$ binding. For the LH assay, unfrozen urine samples were run undiluted in duplicate, indexed for $\mathrm{Cr}$ and expressed as pg $\mathrm{LH} \mathrm{mg}^{-1} \mathrm{Cr}$. The LH assay was also validated using Sumatran rhinoceros serum by demonstrating parallelism to the standard curve of serially diluted Sumatran rhinoceros serum samples (neat to 1:16) previously determined by radioimmunoassay to contain high and low concentrations of LH.

\section{Daily observations}

\section{Study no. 2}

Indian rhinoceros keeper staff filled out daily observation sheets detailing specific information on the female and the male. On the sheet, keeper staff documented the amount of feed given to and eaten by the female, time out and in from exhibit, and behavioural observations. The female was given a small amount of fresh male Indian rhinoceros faecal sample on a daily basis to monitor her behavioural response. In addition, the days in which the female excreted vaginal discharge were noted. Daily rectal temperatures were taken on the female during the early morning of days 368 to 439 of the study (24/10/02 to $3 / 1 / 03)$. Daily information was also collected on the male Indian rhinoceros. These observations included vocalization, change in appetite and degree of ease or difficulty met by keeper staff in getting the male out on exhibit or moving him from one stall to another.

\section{GnRH treatment trials}

\section{Study no. 2}

A GnRH injection was tested during two separate oestrous cycles of the female Indian rhinoceros. A single injection of GnRH (Cystorelin; $50 \mu \mathrm{g} \mathrm{ml}^{-1}(\mathrm{w} / \mathrm{v}) \mathrm{GnRH}$ diacetate tetrahydrate, $10 \mathrm{ml}$ i.m.; CEVA Laboratories, Overland Park, KS, USA) was administered via remote dart delivery on the day of behavioural oestrus, peak urinary $\mathrm{E}_{1} \mathrm{C}$ concentrations and ultrasound evidence of a preovulatory follicle (diameter $>10 \mathrm{~cm}$ ). In the first trial, an ultrasound was conducted at $4 \mathrm{~h}$ post-injection and then every $6 \mathrm{~h}$ until $76 \mathrm{~h}$ post-injection. In the second trial, an ultrasound was conducted at $4 \mathrm{~h}$ post-injection and then every $6 \mathrm{~h}$ until $48 \mathrm{~h}$ post-injection. Throughout both trials, aliquots of all urine samples excreted by the female were collected, stored at $4{ }^{\circ} \mathrm{C}$ and subsequently assayed for $\mathrm{LH}$ concentrations.

\section{Statistical analyses}

The Sigma Plot/Sigma Stat software program (SPSS Inc., Chicago, IL, USA) was used for statistical analyses. Pearson product moment correlation was used to compare the serial dilutions of urine to the standard curve for all assays. Standard descriptive statistics were used to summarize results and statistical significance was tested using Student's $t$-test. Oestrous cycle length was calculated in two ways: based on the date ovulation was detected by rectal ultrasonography and based on alignment of peak urinary oestrogen conjugate concentrations. The lengths of the follicular phase and luteal phase of all oestrous cycles were calculated. The follicular phase started on the day urinary $\mathrm{E}_{1} \mathrm{C}$ concentrations rose above baseline and ended on the day ovulation was detected by rectal ultrasonography. The luteal phase started on the day of ovulation and ended on the day urinary PdG concentrations returned to baseline. Means \pm standard deviation (S.D.) are reported. The hormone data for the three oestrous cycle patterns exhibited by female no. 238 were aligned according to the day of behavioural oestrus. Values were arranged in periods of 15 days before and 30 days after behavioural oestrus and are graphically presented as means \pm standard error of the mean (S.E.M.). For oestrous cycles associated with two separate days of behavioural oestrus, data were aligned according to the second behavioural oestrus. The three oestrous cycle patterns were compared using one-way analysis of variance (ANOVA). If a statistically significant difference resulted, pairwise multiple comparison procedures were employed using the Student-NewmanKeuls method if equal variance passed and the KruskalWallis one-way ANOVA on ranks if equal variance failed. Regression analysis was employed to characterize the follicular growth pattern for each of the three oestrous cycle patterns exhibited by female no. 238 in Study no. 2.

\section{Results}

\section{Studies 1 and 2}

\section{Oestrous cycle dynamics}

The ultrasonographic and endocrine dynamics obtained from individual oestrous cycles $(n=22)$ in the two female Indian rhinoceroses studied are presented in Table 1. In both females, a dominant follicle grew on one of the 


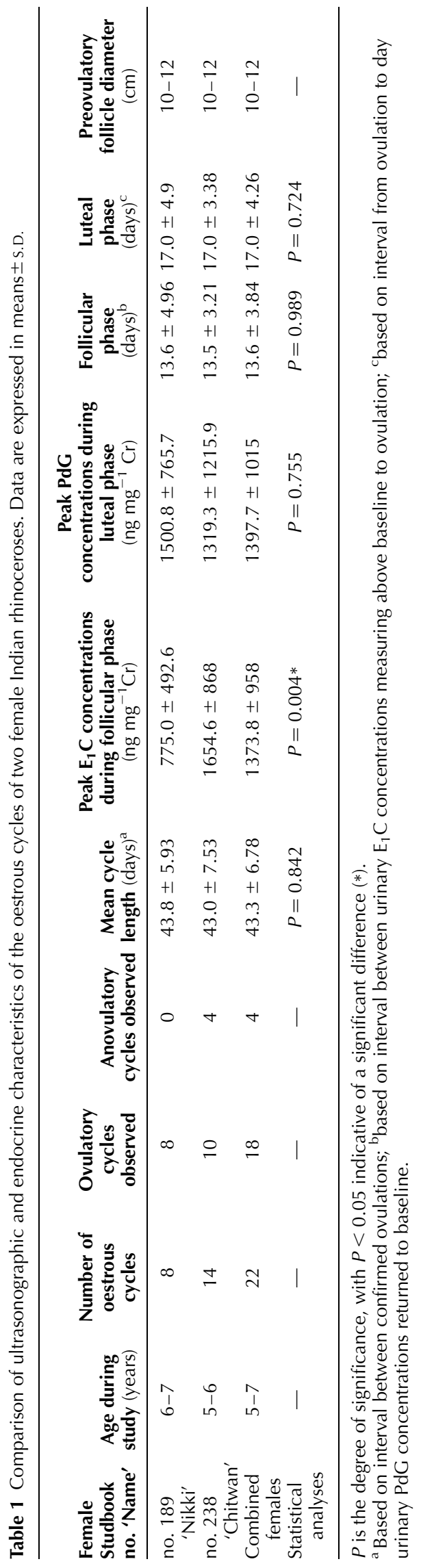

ovaries and reached a maximal diameter of $10-12 \mathrm{~cm}$ prior to ovulation (Fig. 1a). It was not until the follicle reached $>9 \mathrm{~cm}$ in diameter in female no. 189, and $>8 \mathrm{~cm}$ in diameter in female no. 238, that $\mathrm{E}_{1} \mathrm{C}$ concentrations rose above baseline. Baseline $\mathrm{E}_{1} \mathrm{C}$ concentrations for female no. 189 and no. 238 were $16.0 \pm 21.0$ and $48.1 \pm 37.7 \mathrm{ng} \mathrm{mg}^{-1} \mathrm{Cr}$ respectively. Urine samples with $\mathrm{E}_{1} \mathrm{C}$ concentrations $>58.0 \mathrm{ng} \mathrm{mg}^{-1} \mathrm{Cr}$ for female no. 189 and $>123 \mathrm{ng} \mathrm{mg}^{-1} \mathrm{Cr}$ for female no. 238 were above baseline and marked the beginning of the follicular phase. While there was no statistical difference in the length of the follicular phase, the mean peak $E_{1} C$ concentrations measured during the follicular phase differed $(P<0.05)$ between females, with female no. 189 producing lower peak $\mathrm{E}_{1} \mathrm{C}$ concentrations (Table 1). Ovulation was verified by rectal ultrasonography in all oestrous cycles monitored in female no. 189 and in $71 \%$ of the oestrous cycles monitored in female no. 238. Ovulation was characterized by complete follicular collapse (Fig. 1b) followed 1 day later by the formation of a corpus haemorrhagicum (Fig. 1c). The length of the oestrous cycle, based on one complete interovulatory interval, did not differ between females. Similarly, based solely on the interval between peak $\mathrm{E}_{1} \mathrm{C}$ concentrations, mean cycle length in the two females was $43.0 \pm 6.0$ days. The luteal phase in the two females did not differ in length or in the peak urinary PdG concentrations achieved. Fluid was often observed within the lumen of the uterine horns $17.0 \pm 2.35$ days following ovulation (Fig. 1d), which corresponded to the time of precipitous decline in urinary PdG concentrations.

\section{Study no. 2}

\section{Female and male Indian rhinoceros behaviour}

Behavioural oestrus was identified by specific changes in the female's behaviour that included a marked decrease in appetite, an increase in activity level, vocalization and frequent urine spraying associated with vulva winking. In all cycles, the male Indian rhinoceros showed behavioural changes that preceded behavioural oestrus of the female by $2-3$ days. These changes included inappetance overnight, an increase in vocalization (whistling and roaring) when both indoors and outdoors, and extreme resistance to leaving the barn where the female was held.

\section{Ovulatory oestrous cycle dynamics}

Of the 14 oestrous cycles monitored by rectal ultrasonography in female no. 238, a total of ten cycles were associated with successful ovulation (Fig. 2). The growth of the preovulatory follicle and subsequent ovulation occurred with equal frequency from both ovaries. Based on the interval between follicular collapses, ovulatory oestrous cycles ranged in length from 36 to 61 days and were characterized by two distinct behavioural patterns. The female either exhibited 1 day of behavioural oestrus with ovulation occurring $48 \mathrm{~h}$ post oestrus ( $n=6$ cycles), or 

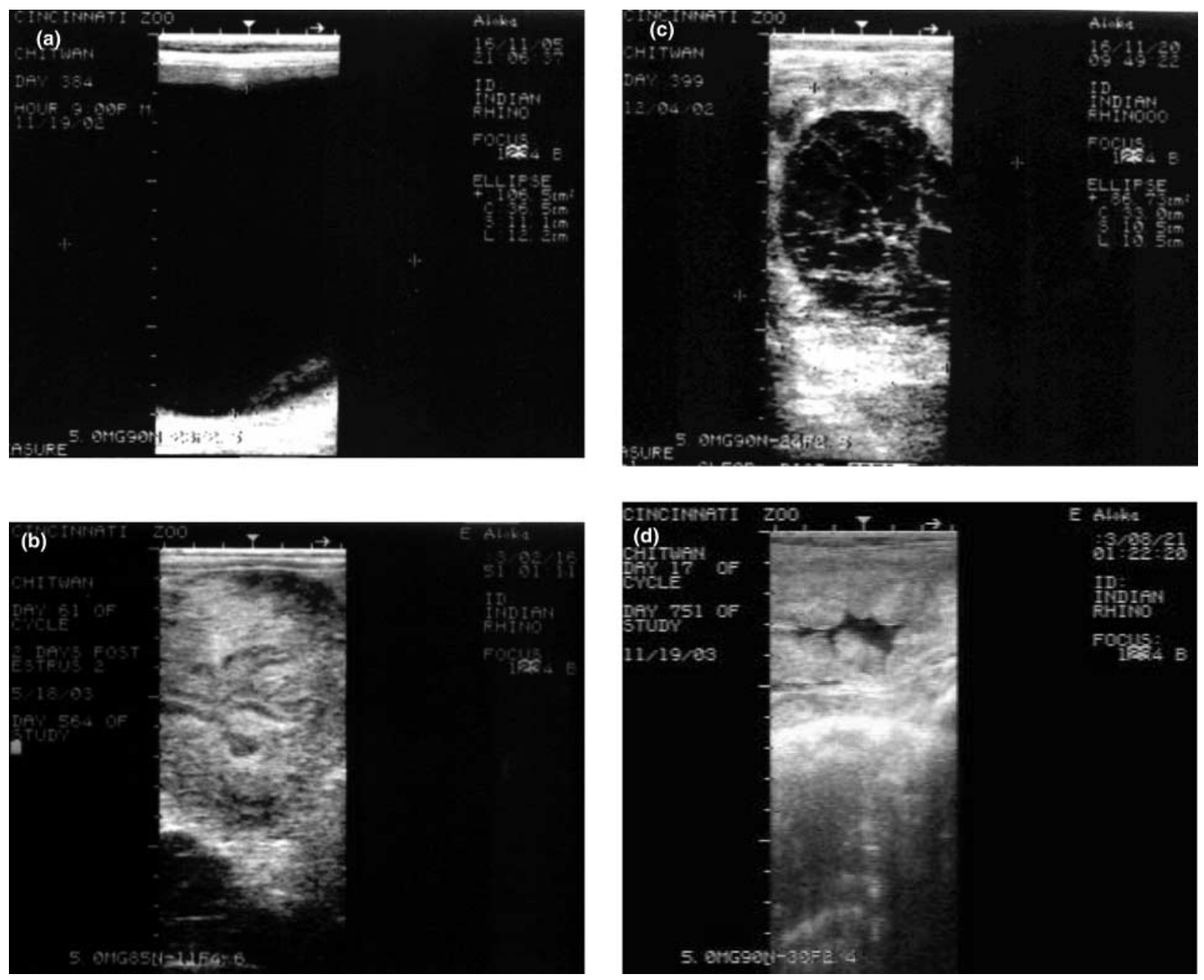

Figure 1 Ultrasonographic images obtained during the oestrous cycles of female 238. (a) Preovulatory follicle associated with an oestrous cycle in which 1 day of behavioural oestrus was exhibited. This ultrasonographic image of the preovulatory follicle was taken $39 \mathrm{~h}$ post oestrus and only $9 \mathrm{~h}$ prior to ovulation. (b) Ultrasonographic image of follicular collapse that confirmed ovulation $48 \mathrm{~h}$ post-oestrus. (c) A day 15 corpus haemorrhagicum that had organizing criss-crossing fibrin strands. (d) Ultrasonographic image of fluid within the lumen of the uterine horn day 17 post ovulation.

she exhibited 1 day of behavioural oestrus, followed by $1-3$ days of normal behaviour, then a second day of behavioural oestrus with ovulation occurring $48 \mathrm{~h}$ later $(n=4$ cycles). The two behavioural patterns were associated with cycles of different length or interovulatory period $(P<0.05)$, with the oestrous cycle averaging $37.8 \pm 1.95$ days for the former and $49.0 \pm 8.58$ days for the latter (Fig. 2). No differences $(P>0.05)$ were observed in the length of the follicular or luteal phases between the two patterns. The follicular phase was $13.17 \pm 3.43$ days for oestrous cycles with one behavioural oestrus and $14.0 \pm 3.74$ days for those with 2 separate days of behavioural oestrus. The mean concentrations of $E_{1} C$ during the follicular phase were similar $(P>0.05)$ between ovulatory cycles with one or 2 separate days of behavioural oestrus $\left(1475.8 \pm 475 \mathrm{ng} \mathrm{mg}^{-1} \mathrm{Cr}\right.$ and $2567.8 \pm 1219.5 \mathrm{ng} \mathrm{mg}^{-1} \mathrm{Cr}$ respectively) (Fig. 3a,b). However, urinary $\mathrm{E}_{1} \mathrm{C}$ concentrations on the day of behavioural oestrus were higher $(P<0.05)$ in oestrous cycles with 2 separate days of behavioural oestrus versus cycles with one day of behavioural oestrus. In those oestrous cycles in which 2 separate days of behavioural oestrus were exhibited, urinary $\mathrm{E}_{1} \mathrm{C}$ remained at peak concentrations throughout the day(s) between oestrus exhibitions (Fig. 3b). With both behavioural patterns, $\mathrm{E}_{1} \mathrm{C}$ concentrations reached baseline $3.9 \pm 1.37$ days following the oestrus that preceded ovulation (Fig. 3a,b). The preovulatory follicle was always present at $36 \mathrm{~h}$ post-oestrus but had collapsed at $48 \mathrm{~h}$. Within $24 \mathrm{~h}$ following confirmation of follicular collapse, the central clot of the corpus haemorrhagicum was detectable by ultrasound. A transient rise in PdG concentrations $\left(>200 \mathrm{ng} \mathrm{mg}^{-1} \mathrm{Cr}\right.$ ) was measured in urine collected 1 day following oestrus, which corresponded to the day prior to ovulation (Fig. $3 a, b)$. The sustained rise in urinary PdG concentrations indicating the initiation of luteal tissue formation and 


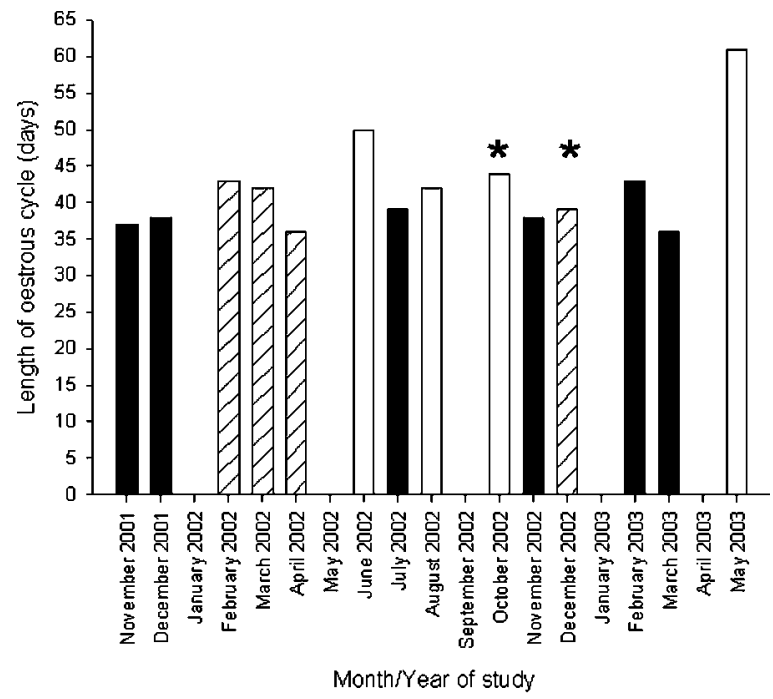

Figure 2 Longitudinal profile of the occurrence and length of the three oestrous cycle patterns exhibited by female no. 238 during Study no. 2. Length of the oestrous cycle was based on the interval between ultrasonographic confirmation of ovulation for ovulatory cycles, and the day of behavioural oestrous for anovulatory cycles. The study encompassed 14 oestrous cycles. A total of 10 ovulatory cycles occurred that were associated with either 1 (solid bars, $n=6$ ) or 2 (open bars, $n=4$ ) days of oestrus behaviour. In addition, four anovulatory cycles (hatched bars) were documented that were associated with 1 day of behavioural oestrus. GnRH treatment $(*)$ was tested in two separate oestrous cycles.

function occurred 5 days following ultrasonographic confirmation of ovulation (Fig. 3a,b). Neither the length of the luteal phase $(17.0 \pm 3.38)$ nor peak PdG concentrations $\left(1319.3 \pm 1215.9 \mathrm{ng} \mathrm{mg}^{-1} \quad \mathrm{Cr}\right)$ differed $(P>0.05)$ between cycles associated with the two different behavioural patterns (Fig. 3a,b).

\section{Anovulatory oestrous cycle dynamics}

A total of four anovulatory oestrous cycles were diagnosed in female no. 238 by rectal ultrasonography (Table 1). Anovulatory oestrous cycles were associated with just 1 day of behavioural oestrus followed by the formation of a haemorrhagic follicle. The female grew a follicle on one of the ovaries that reached a mean diameter of $11.1 \pm 0.97 \mathrm{~cm}$ on the day of behavioural oestrus (Fig. 4a). Peak $\mathrm{E}_{1} \mathrm{C}$ concentrations excreted during these cycles measured $1155.0 \pm 306.4 \mathrm{ng} \mathrm{mg}^{-1} \mathrm{Cr}$ and became baseline $5.3 \pm 3.3$ days post-oestrus (Fig. 3c). Urinary $\mathrm{E}_{1} \mathrm{C}$ concentrations were lower $(P<0.05)$ on the day of behavioural oestrus in anovulatory compared with ovulatory oestrous cycles (Fig. 3a,b,c). Because no follicular collapse was associated with anovulatory cycles, day 0 of these cycles was determined by the day of behavioural oestrus. Anovulatory oestrous cycles had a mean cycle length of $40 \pm 3.16$ days (Fig. 2). Anovulatory follicles occurred three separate times on the right ovary and once on the left ovary. The four anovulatory oestrous cycles occurred from January to April 2002 and again in
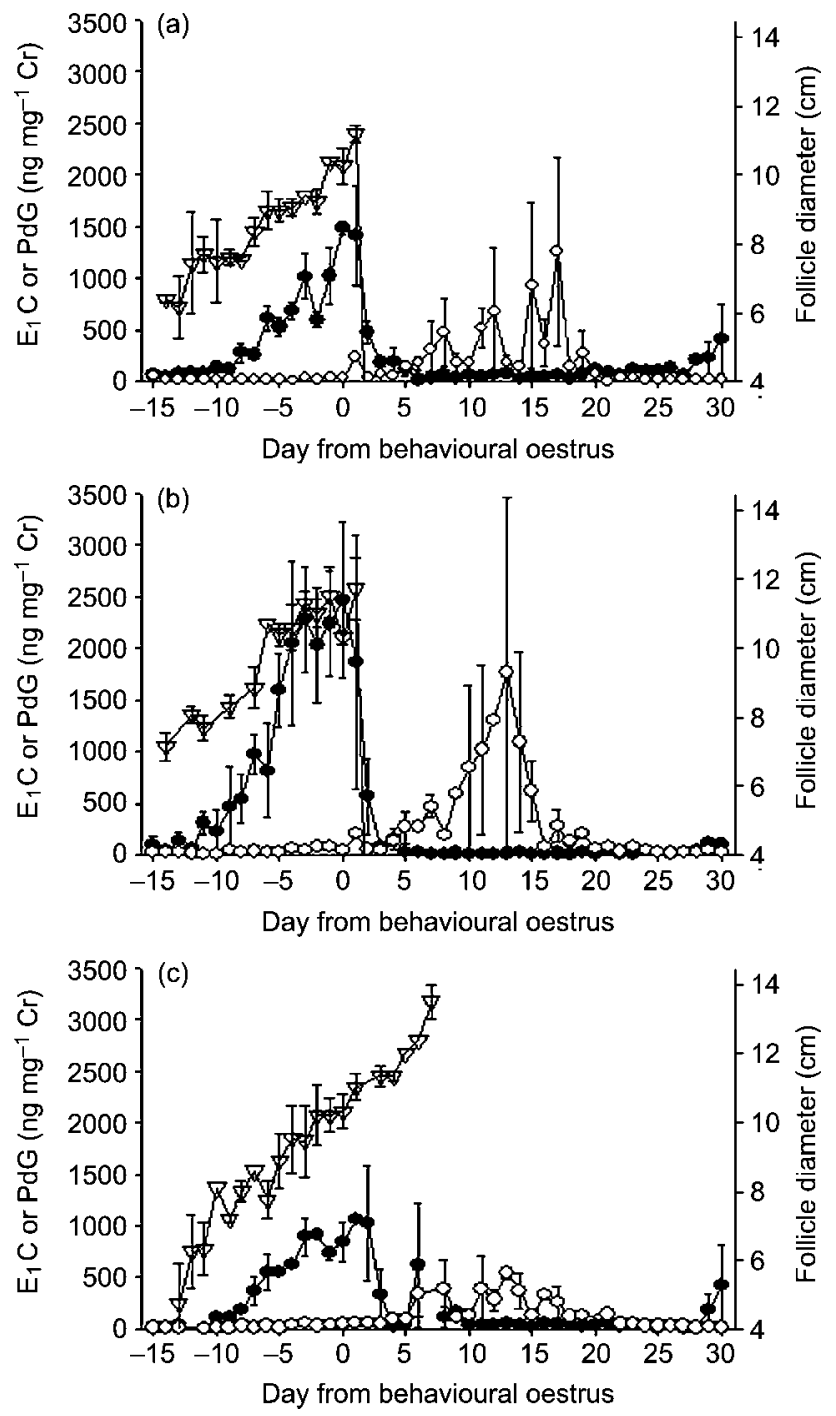

Figure 3 Composite profiles of the follicular growth pattern of the dominant follicle $(\nabla)$ and urinary oestrogen conjugate $\left(\mathrm{E}_{1} \mathrm{C}, \bullet\right)$ and progesterone metabolite $(\mathrm{PdG}, \mathrm{O})$ concentrations (mean \pm S.E.M.) excreted throughout the oestrous cycle for the three patterns exhibited by female no. 238. Data are aligned from the day of behavioural oestrous. (a) Profile for ovulatory oestrous cycles associated with 1 day of behavioural oestrus ( $n=6$ cycles). (b) Profile for ovulatory oestrous cycles associated with 2 separate days of behavioural oestrus ( $n=4$ cycles). For those ovulatory oestrous cycles associated with 2 separate days of behavioural oestrus, day 0 corresponds to the second behavioural oestrus. (c) Profile for anovulatory oestrous cycles associated with the formation of a haemorrhagic follicle ( $n=4$ cycles).

December 2002 (Fig. 2). Haemorrhagic follicles were diagnosed based on persistent maximal follicle diameter following behavioural oestrus, in some cases exceeding the preovulatory diameter (range $12.9-14.9 \mathrm{~cm}$; Fig. 3c), no occurrence of follicular collapse, and the presence of uncoagulated blood swirling within the follicle upon ballottement (Ginther 1995). These follicles progressed from containing slightly echogenic follicular fluid to eventual complete infiltration of the follicular lumen (Fig. 4b). As 

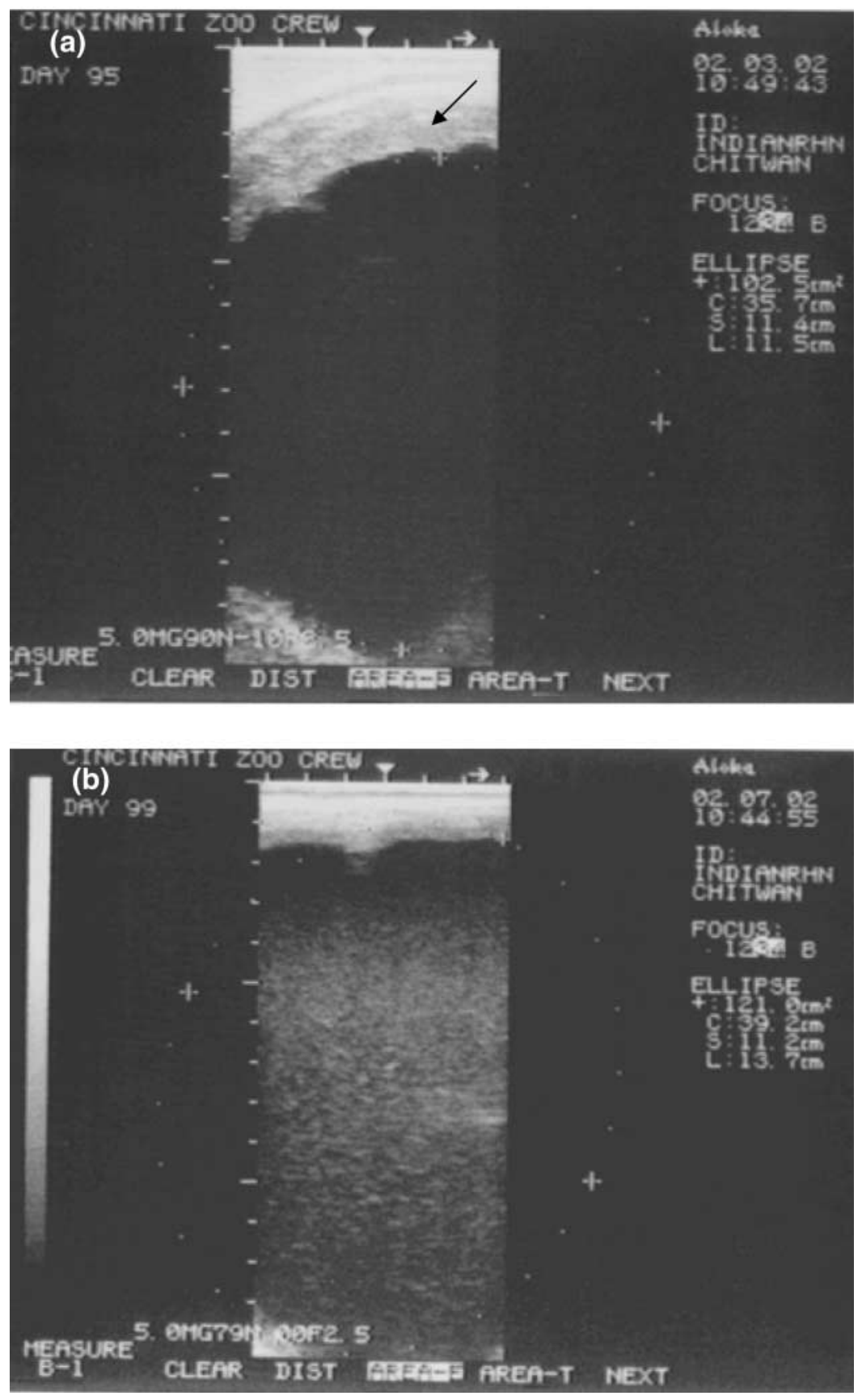

Figure 4 Ultrasonographic images obtained during the oestrous cycles of female no. 238. (a) Ultrasonographic image of an anovulatory follicle on the day of behavioural oestrus. Note the similar size to the preovulatory follicle (Fig. 1a) and the thickened follicular wall (arrow) indicative of estrogen producing cells. (b) Ultrasonographic image of an anovulatory haemorrhagic follicle 4 days following behavioural oestrus. Note the echogenicity of the follicular fluid and the thinning follicular wall. Upon ballottement, the fluid within the follicle swirled. (c) A day 8 anovulatory haemorrhagic follicle. Note the distinct pockets observed within the structure. While the upper pocket (UP) had distinct gel-like bands, fluid was observed to swirl in the lower pocket (LP) upon ballottement. (d) Ultrasonographic image of a large fluid-filled structure diagnosed as a follicular cyst. Note the absence of a thickened follicular wall. the haemorrhagic follicles slowly filled, they formed distinct pockets containing fluid and fibrin bands (Fig. 4c). These follicles gradually regressed and were no longer visible by ultrasound at 30 days. All anovulatory cycles were associated with some PdG production post oestrus, but peak concentrations were markedly lower $\left(607.3 \pm 305.9 \mathrm{ng} \mathrm{mg}^{-1} \mathrm{Cr}\right.$ ) than those measured for oestrous cycles associated with successful ovulation (Fig. 3c). No transient rise in PdG concentrations was measured in urine collected 1 day following oestrus in any of the four anovulatory oestrous cycles observed (Fig. 3c).

\section{Follicular growth pattern}

In all cycles monitored, several small follicles $(1-5 \mathrm{~cm})$ often developed early in the cycle but only one grew further to become a dominant preovulatory follicle. Ovulatory oestrous cycles with one occurrence of behavioural oestrus were associated with emergence of the dominant follicle earlier in the cycle compared with the other oestrous cycle patterns. Growth of the dominant follicle during ovulatory oestrous cycles did not differ between the two behavioural patterns and occurred at a rate of $0.39 \pm 0.04 \mathrm{~cm} \mathrm{day}^{-1}$ once the follicle reached 
$6 \mathrm{~cm}$ in diameter until maximal diameter was achieved. However, the length of time maximal follicle diameter was maintained prior to ovulation did differ between the two behavioural patterns, with the dominant follicle retained $3.2 \pm 1.79$ days (Fig. 3a) prior to ovulation in cycles with one behavioural oestrus versus $7.75 \pm 1.5$ days (Fig. $3 \mathrm{~b}$ ) in cycles with 2 separate days of behavioural oestrus. Growth of the dominant follicle for anovulatory cycles occurred at a rate of $0.32 \pm 0.04 \mathrm{~cm}$ day $^{-1}$ once the follicle reached $6 \mathrm{~cm}$ in diameter until a $10 \mathrm{~cm}$ diameter was achieved. The anovulatory follicles then grew at $0.5 \pm 0.06 \mathrm{~cm}$ day $^{-1}$ until infiltration was complete (Fig. 3c).

\section{Follicular cyst}

There was one cycle in which a follicular cyst formed that resulted in the extension of an ovulatory oestrous cycle to 61 days (Fig. 2; Fig. 4d). The female quickly grew a large follicle on the right ovary that reached a $9 \mathrm{~cm}$ diameter by day 24 of the cycle and reached a maximal diameter of $11 \mathrm{~cm}$ by day 45 of the cycle. Throughout the growth of the follicle, it appeared thin walled, and urinary $\mathrm{E}_{1} \mathrm{C}$ and $\mathrm{PdG}$ concentrations remained at baseline. From day 38 to day 61 of the oestrous cycle, the left ovary developed a follicle that grew to become the preovulatory follicle. The follicular cyst gradually declined from $7 \mathrm{~cm}$ on day 48 to $4 \mathrm{~cm}$ on day 54 of the oestrous cycle.

\section{Vaginal discharge}

Vaginal discharge for ovulatory cycles associated with one behavioural oestrus occurred at a mean of 3.5 days post oestrus and lasted 7 days post ovulation. Vaginal discharge was noted prior to ovulation in those ovulatory oestrous cycles with two exhibitions of behavioural oestrus. The pattern of discharge for these cycles was 1 day following the second oestrus through 7 days post ovulation. In the case of anovulatory cycles, only 1 day of vaginal discharge was noted at 5 days post oestrus.

\section{Rectal temperatures throughout the oestrous cycle}

During two separate oestrous cycles, rectal temperatures were taken daily. Both cycles were associated with just one day of behavioural oestrus. In November 2002, the female completed a successful ovulatory cycle and in December 2002 an anovulatory cycle occurred. Mean rectal temperature throughout these two cycles was $37.1^{\circ} \mathrm{C}$. The day of behavioural oestrus for each of the two cycles was associated with a rise in rectal temperature to $38.2^{\circ} \mathrm{C}$ and $38.0{ }^{\circ} \mathrm{C}$ respectively $(P<0.05)$.

\section{LH EIA validation}

A parallel dose-response was observed between serially diluted (neat to 1:32) female Indian rhinoceros urine samples and bovine $\mathrm{LH}$ standards throughout the range of the curve. The correlation coefficient between the standard and pooled urine was $0.992(P<0.05)$.
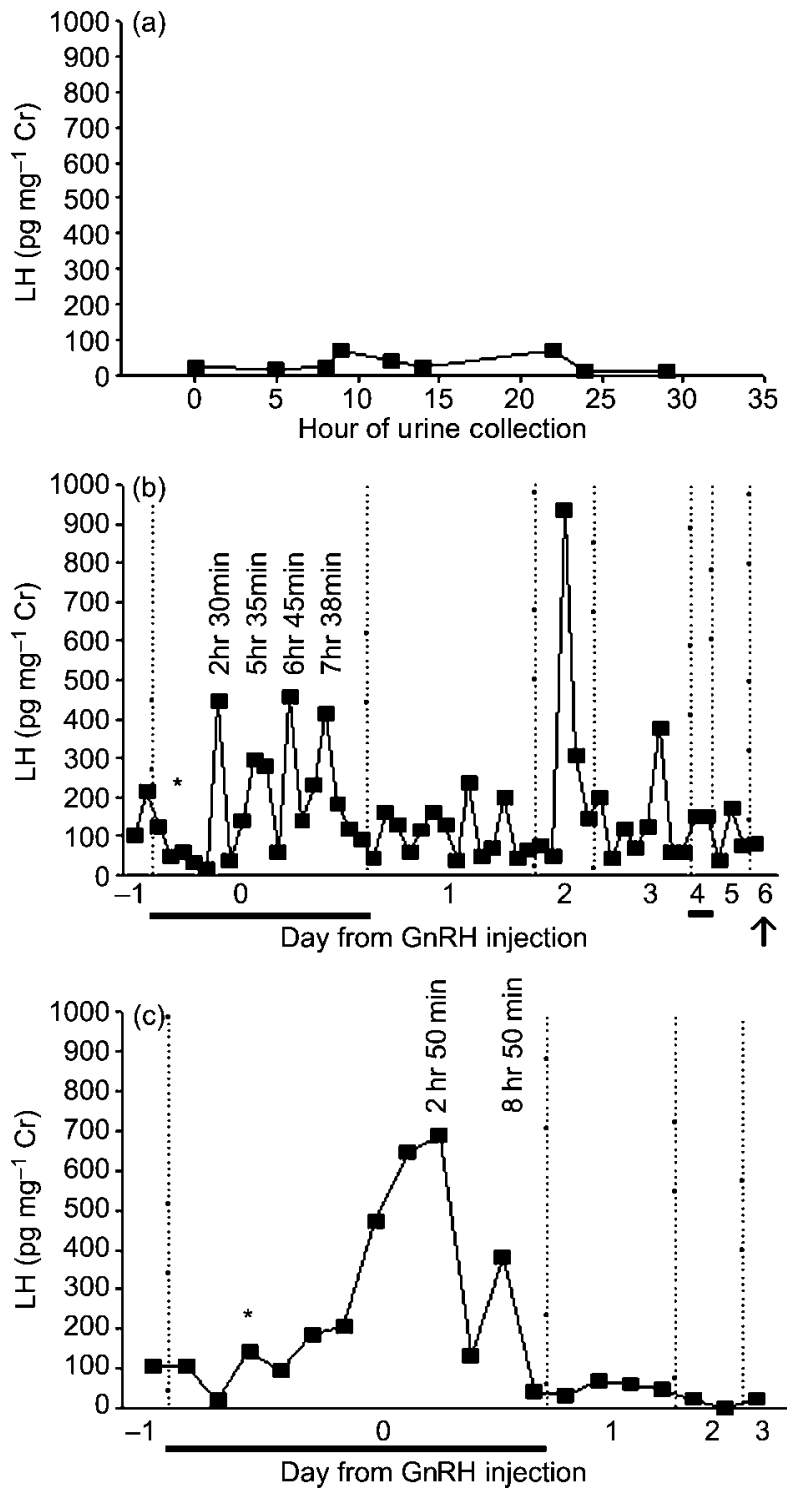

Figure 5 Urinary LH profiles excreted by female no. 238. (a) Baseline $\mathrm{LH}$ concentrations excreted during a $24 \mathrm{~h}$ period of day 29 and day 30 of an oestrous cycle. (b) Pattern of LH excretion following a $\mathrm{GnRH}$ injection (*) administered during the first oestrus of an ovulatory oestrous cycle associated with two separate days of behavioural oestrous. (c) Pattern of LH excretion following a GnRH injection $(*)$ administered during oestrus of an anovulatory oestrous cycle. Days on which behavioural oestrus were observed are noted by thick black lines below the $x$-axis and the day ovulation was detected by rectal ultrasonography is denoted by an arrow.

\section{Baseline urinary $\mathrm{LH}$}

Mean urinary LH concentration excreted during a $24 \mathrm{~h}$ time period on days 29 and 30 of an oestrous cycle was $34.7 \pm 8.52 \mathrm{pg} \mathrm{mg}^{-1} \mathrm{Cr}$ (Fig. 5a).

\section{GnRH treatment Trial no. 1}

On 7 October 2002 (day 38 of the oestrous cycle), the female exhibited behavioural signs of oestrus. An 
ultrasound conducted on the morning of oestrus detected a follicle measuring $11.8 \mathrm{~cm}$ in diameter and the $\mathrm{E}_{1} \mathrm{C}$ concentration of an early morning urine sample was $1213 \mathrm{ng}$ $\mathrm{mg}^{-1} \mathrm{Cr}$. At $1157 \mathrm{~h}$ on 7 October $2002500 \mu \mathrm{g} \mathrm{GnRH}$ were administered to the female. Retrospective LH EIA analysis of urine samples collected from Trial no. 1 indicated that four LH surges occurred on the day of oestrus following the $\mathrm{GnRH}$ injection (Fig. 5b). The first $\mathrm{LH}$ surge was measured in urine $2 \mathrm{~h}$ and $30 \mathrm{~min}$ following $\mathrm{GnRH}$ injection with the fourth surge measured at $7 \mathrm{~h}$ and $38 \mathrm{~min}$. On day 2 and 3 post-GnRH injection, LH surges that measured 936 and $374 \mathrm{pg} \mathrm{mg}^{-1} \mathrm{Cr}$ respectively were detected (Fig. 5b). The female exhibited a second behavioural oestrus on the fourth day after $\mathrm{GnRH}$ injection. Ovulation was detected by rectal ultrasonography on day 6 post-GnRH injection, $48 \mathrm{~h}$ after the second behavioural oestrus. Mean $\mathrm{E}_{1} \mathrm{C}$ concentrations measured $>1000 \mathrm{ng}$ $\mathrm{mg}^{-1} \mathrm{Cr}$ throughout the trial until the day of ovulation, when the mean concentration measured $407 \mathrm{ng} \mathrm{mg}^{-1} \mathrm{Cr}$. Mean PdG concentrations measured $39.7 \pm 33.0 \mathrm{ng} \mathrm{mg}^{-1}$ $\mathrm{Cr}$ throughout the trial until day 5 post-GnRH injection when the mean concentration measured $203 \mathrm{ng} \mathrm{mg}^{-1} \mathrm{Cr}$. Day 5 post-GnRH injection corresponded to 1 day after the second oestrus, and 1 day prior to ovulation. Throughout the trial, LH appeared pulsatile and was consistently above baseline.

\section{GnRH treatment Trial no. 2}

On 29 December 2002 (day 39 of the oestrous cycle), the female exhibited behavioural signs of oestrus. An ultrasound conducted on the morning of oestrus detected a follicle measuring $12 \mathrm{~cm}$ in diameter and the urinary $\mathrm{E}_{1} \mathrm{C}$ concentration was $900 \mathrm{ng} \mathrm{mg}^{-1} \mathrm{Cr}$. The female was given $500 \mu \mathrm{g} \mathrm{GnRH}$ at $1200 \mathrm{~h}$ on the day of oestrus. Retrospective analysis of urine samples collected from Trial no. 2 indicated that two $\mathrm{LH}$ surges (690 and $384 \mathrm{pg} \mathrm{mg}^{-1} \mathrm{Cr}$ ) occurred following $\mathrm{GnRH}$ injection (Fig. 5c). The first surge was measured in the urine $2 \mathrm{~h}$ post-GnRH injection with the second surge detected at $8 \mathrm{~h}$ and $50 \mathrm{~min}$. Urinary $\mathrm{E}_{1} \mathrm{C}$ concentrations remained elevated throughout the trial (day 0 -day 2; 934, 665 and $478 \mathrm{ng} \mathrm{mg}^{-1} \mathrm{Cr}$ respectively) until day 3 post-GnRH injection, when the mean concentration measured $59.09 \mathrm{ng} \mathrm{mg}^{-1} \mathrm{Cr}$. No measurable rise in PdG concentrations occurred during the trial $\left(43.1 \pm 15.82 \mathrm{ng} \mathrm{mg}^{-1} \mathrm{Cr}\right)$. Urinary $\mathrm{LH}$ concentrations were relatively flat on days 1 and 2 post-GnRH injection reaching baseline $\left(30.48 \mathrm{pg} \mathrm{mg}^{-1} \mathrm{Cr}\right.$ ) on day 3 . Ovulation did not occur. Instead, an anovulatory haemorrhagic follicle was diagnosed by rectal ultrasonography on day 3 post-GnRH injection, based on echogenicity of follicular fluid and swirling of the fluid upon ballottement.

\section{Discussion}

The Indian rhinoceros appears to exhibit several speciesspecific reproductive characteristics among the Rhinocerotidae. First, changes in oestrogen concentrations are readily measured in the urine and/or faeces and reflect cyclical patterns, whereas in the Sumatran, African black and African white rhinoceros oestrogen metabolite analyses have not proven reliable as a means of monitoring ovarian function (Ramsay et al. 1987, Hodges \& Hindle 1988, Roth et al. 2001). Futhermore, studies characterizing the reproductive cycle through the measurement of excreted steroid hormone concentrations and animal behaviour revealed wide intra- and inter-animal variations in the oestrous cycle length of this species (Kassam \& Lasley 1981, Kasman et al. 1986, Schwarzenberger et al. 2000). In this study, ultrasonography was employed for the first time in this species to investigate the dynamics of follicular growth, precise timing of ovulation and the subsequent formation and demise of luteal tissue in relation to endocrine and behavioural patterns. Our findings unveil several additional characteristics that appear specific to this species and also provide information that may help explain both earlier findings by researchers and the difficulties encountered by zoo personnel trying to breed the Indian rhinoceros.

Both female Indian rhinoceroses monitored in the study exhibited strikingly similar oestrous cycle dynamics. The growth of very large follicles appeared characteristic for this species and was not an individual or aberrant cycle specific phenomenon. The diameter of the preovulatory follicle $(10-12 \mathrm{~cm})$ in the Indian rhinoceros far exceeds that for other species within the Perissodactyla order. Preovulatory follicles in the domestic horse reach 3.5 to $5.5 \mathrm{~cm}$ in diameter (Ginther 1995, Carnedale 1998). Both African species of rhinoceros grow preovulatory follicles similar in diameter to those of the horse (Radcliffe et al. 1997, 2001), whereas the Sumatran rhinoceros grows smaller preovulatory follicles measuring just 1.9 to $2.5 \mathrm{~cm}$ in diameter (Roth et al. 2001). In fact, no other species of mammal is known to grow such large preovulatory follicles. Even a species much larger than the Indian rhinoceros, the elephant, produces follicles that measure only $2.1 \mathrm{~cm}$ in diameter (Hermes et al. 2000, Hildebrandt et al. 2000).

Data in this study indicate that a single wave of follicular development is associated with each Indian rhinoceros oestrous cycle, a finding similar to that reported for African and Sumatran species (Radcliffe et al. 1997, 2001, Roth et al. 2001). Whereas the Sumatran rhinoceros and domestic horse can develop multiple antral follicles (Ginther 1995, Carnedale 1998, Roth et al. 2001), both Indian rhinoceroses in this study developed a single antral follicle on one of the ovaries similar to that which has been reported for the African species (Radcliffe et al. 1997, 2001). In many species including the domestic horse, Sumatran, African black and African white rhinoceros, maximum follicle size has proven useful in predicting impending oestrus and ovulation (Ginther 1995, Carnedale 1998, Radcliffe et al. 1997, 2001, Roth et al. 2001). In contrast, the preovulatory follicle of the Indian rhinoceros achieved its maximum diameter several days 
up to 1 week prior to behavioural signs of oestrus. Furthermore, no observable change in the shape of the preovulatory follicle was detected prior to ovulation, as has been reported to occur in the domestic horse, African black and African white rhinoceros (Ginther 1995, Carnedale 1998, Radcliffe et al. 1997, 2001).

Ovulation occurred spontaneously in both the female Indian rhinoceroses as it does in the horse, African black and African white rhinoceros (Ginther 1995, Carnedale 1998, Radcliffe et al. 1997, 2001), differentiating the Indian species from its Asian relative, the Sumatran rhinoceros, that appears to be an induced ovulator. In both female Indian rhinoceroses, ovulation was consistently followed by formation of a corpus haemorrhagicum. In contrast, the African white rhinoceros appears capable of forming both corpora lutea and corpora haemorrhagica (Radcliffe et al. 1997), while corpora haemorrhagica were never observed following ovulation in the Sumatran rhinoceros (Roth et al. 2001). We also documented four oestrous cycles in the younger female Indian rhinoceros associated with anovulation and the production of haemorrhagic follicles. Three of the anovulatory cycles occurred from January to May of 2002, with the fourth anovulatory cycle occurring in late December 2002. Anovulatory haemorrhagic follicles have been reported to occur in the domestic horse, African black and African white rhinoceros (Ginther 1995, McKinnon 1998, Radcliffe et al. 1997, 2001). In the domestic horse, these follicles are associated with the transition into winter anoestrus and the formation of accessory corpora lutea of pregnancy (Ginther 1995, McKinnon 1998). Researchers have provided evidence that insufficient gonadotrophin stimulation to induce ovulation and insufficient oestrogen production from the follicle itself may be responsible for their occurrence (Irvine et al. 2000, Watson et al. 2002). Radcliffe et al. $(1997,2001)$ documented the occurrence of anovulatory haemorrhagic follicles in captive African black and African white rhinoceros, hypothesizing seasonal and/or management activities as possible causes for the decline in fertility. Recently, researchers provided endocrine evidence of seasonality in the wild African black rhinoceros (Garnier et al. 2002). Through longitudinal faecal hormone analysis, these researchers established a 3 month period of decreased fertility that correlated to changes in the environmental factors of photoperiod, rainfall and temperature (Garnier et al. 2002). The Sumatran rhinoceros has also been reported to develop luteinized follicles that were anovulatory, but their occurrence was associated with absence of the mating activity necessary to induce ovulation and was not related to season (Roth et al. 2001). Although the reason why the one Indian rhinoceros developed anovulatory follicles is unknown, it is possible they occurred due to reduced photoperiod during the winter months. The fluorescent lights in the stalls housing the female were changed to a fixed $14 \mathrm{~h}$ exposure regimen following the December 2002 anovulatory oestrous cycle, and the female successfully ovulated in the oestrous cycles that followed during the winter of 2003 in Study no. 2. However, despite the fixed light regimen, an anovulatory cycle was again observed in this female in April 2004 (M A Stoops, personal observation). Despite some anecdotal evidence of a photoperiod effect on ovulation, it is more likely that the female is simply in transition from a pre-pubertal state to puberty. The second female Indian rhinoceros ovulated in all oestrous cycles monitored and she was a year older. However, there was a 64 day period during winter (November 1998 to February 1999) in Study no. 1 when ultrasounds were not conducted.

Ultrasound data in this study support previous reports of variable cycle length in the Indian rhinoceros (Kasman et al. 1986, Roth \& Brown 1999) with the interval between ovulations ranging from 36 to 61 days. Regardless, when mean cycle length was calculated (43 days) it was very similar to that previously calculated based on intervals between oestrogen peaks (Kassam \& Lasley 1981, Kasman et al. 1986, Schwarzenberger et al. 2000). In this study, the longest cycle (61 days) that occurred in the younger female was associated with the formation of a follicular cyst that lengthened an ovulatory oestrous cycle.

The follicular phase of the Indian rhinoceros appears to be the longest among species in the Perissodactyla order. A follicular phase of $\sim 14$ days was documented in the two females based on the length of time between the rise of urinary $\mathrm{E}_{1} \mathrm{C}$ concentrations above baseline and the day ovulation was detected by rectal ultrasonography. The length of the follicular phase in our study did not differ from those reported by researchers following the rise and fall of oestrogen conjugate concentrations in the urine (Kassam \& Lasley 1981, Kasman et al. 1986), as concentrations were at baseline $\sim 1$ day following ovulation. However, in most mammalian species, growth of the preovulatory follicle can be closely tied to oestrogen production, with the follicular phase an approximate measure of these two highly correlated events. The preovulatory follicle of the Indian rhinoceros could not be reliably predicted until it reached $6 \mathrm{~cm}$ in diameter and it was not until the follicle grew to 8 or $9 \mathrm{~cm}$ in diameter that urinary $\mathrm{E}_{1} \mathrm{C}$ concentrations rose above baseline. Therefore, the length of the follicular phase of the Indian rhinoceros would be considerably longer if based solely on growth of the follicle destined for ovulation. The length of the luteal phase (17 days) reported herein, was similar to the 17-21 days reported in another study of the Indian rhinoceros using urinary hormone analysis (Kasman et al. 1986).

The difference in peak urinary $\mathrm{E}_{1} \mathrm{C}$ concentrations between the two females could be due to variation in the frequency of urine collections between the two study animals. The younger female was more intensively monitored to determine events around the periovulatory period. Daily urine collections were conducted around oestrus, when peak $\mathrm{E}_{1} \mathrm{C}$ concentrations were measured. However, the younger female also had higher baseline urinary $\mathrm{E}_{1} \mathrm{C}$ concentrations suggesting an individual specific differ- 
ence. In fact, prior studies of the Indian rhinoceros reported similar inter-animal differences in hormone concentrations (Kasman et al. 1986, Schwarzenberger et al. 2000). Therefore, a real physiological variation in hormone production between the individual females could account for the observed statistical difference in the data.

Oestrous behaviours in the Indian rhinoceros were similar to those observed in the domestic horse and African rhinoceros species (Hafez 1993, Radcliffe et al. 1997, 2001). When using oestrous behaviour alone or oestrous behaviour in combination with urinary hormone analysis it was almost impossible to distinguish between ovulatory and anovulatory cycles. At no point during the study was the female put with the male for the purpose of breeding, so we cannot attest to whether she would have exhibited 'standing' oestrous behaviour. However, the oestrous behaviours of anovulatory cycles were of similar duration and intensity to those observed during oestrus of ovulatory cycles. Therefore, rectal ultrasonography was critical in determining if ovulation had occurred $48 \mathrm{~h}$ following oestrus. Retrospective analysis revealed that urinary $\mathrm{E}_{1} \mathrm{C}$ concentrations on the day of behavioural oestrus in anovulatory oestrous cycles were statistically lower than $E_{1} C$ concentrations on the day of behavioural oestrus for ovulatory cycles. However, there would be no way to determine whether an oestrous cycle would be anovulatory based on an $E_{1} C$ concentration collected on the day of behavioural oestrus among a population that exhibits such hormonal variation between individuals and cycles. In prior studies of the Indian rhinoceros, researchers interpreted a decline in oestrogen concentration a short time after oestrus as verification of ovulation (Kassam \& Lasley 1981, Kasman et al. 1986, Schwarzenberger et al. 2000). While $\mathrm{E}_{1} \mathrm{C}$ concentrations accurately reflected final follicular growth, a decline in $\mathrm{E}_{1} \mathrm{C}$ occurred even with anovulatory cycles. Further confounding the ability to hormonally distinguish between ovulatory and anovulatory oestrous cycles was the formation of haemorrhagic follicles capable of luteinization and progesterone production. All anovulatory cycles were associated with some, albeit erratic, urinary PdG excretion that could be mistaken for a luteal phase. Similarly, in horses, researchers determined that the majority of anovulatory follicles became luteal structures based on elevated progesterone concentrations (McCue 1998, McCue \& Squires 2002). Ultrasonographic documentation of anovulatory oestrous cycles may have important implications for captive breeding efforts with Indian rhinoceros, because it establishes the occurrence of infertile cycles that otherwise appear fertile through the traditional methods of oestrous behaviour and endocrine monitoring.

Detailed examination of ovulatory oestrous cycles in the younger female revealed two patterns that differed in length, the number of days that oestrous behaviours were exhibited, and the number of days the preovulatory follicle was sustained at maximum diameter and peak urinary $\mathrm{E}_{1} \mathrm{C}$ concentrations. Oestrous cycles associated with two separate days of behavioural oestrus had statistically longer cycle lengths attributable to a delay in the emergence of the preovulatory follicle and more days spent at maximum diameter prior to ovulation. However, despite these differences, several important consistencies existed during the periovulatory period in the two cycle patterns that may prove useful in breeding decisions and/or developing assisted reproductive techniques in the Indian rhinoceros. With both patterns, the female ovulated within $48 \mathrm{~h}$ following a behavioural oestrus. Additionally, a slight, transient rise in urinary $\mathrm{PdG}$ concentrations occurred the day following that oestrus and may be useful in predicting ovulation. Even though Kasman et al. (1986) were unable to verify ovulation through the methods used in their study, they reported a similar rise in urinary PdG concentrations up to 5 days prior to the decline in urinary $\mathrm{E}_{1} \mathrm{C}$. Progesterone has been implicated to play a role in ovulation in many other mammalian species (Kapustin et al. 1996, Zalanyi 2001, Cassar et al. 2002, Jo et al. 2002, Stouffer 2002).

Changes in rectal temperature and vaginal discharge were also investigated as a means of predicting ovulation in the Indian rhinoceros. In humans, an initial drop in basal body temperature is followed by a rise at the time of ovulation (Davis 1946). In the younger Indian rhinoceros, $\mathrm{a} \sim 1{ }^{\circ} \mathrm{C}$ rise in rectal temperature was measured on the day of oestrus for both an ovulatory and anovulatory oestrous cycle. The rise in temperature was attributed to the marked increase in activity level during behavioural oestrus and was not due to the act of ovulation. The occurrence of vaginal discharge in the young female appeared to correlate with progesterone production and was not necessarily verification of ovulation. In ovulatory cycles, the female produced a vaginal discharge shortly after behavioural oestrus, whereas the discharge was delayed in anovulatory cycles, possibly due to slow and/or incomplete luteal tissue formation and function.

In an effort to overcome the challenge of predicting ovulatory cycles, GnRH injections were tested as a means of ensuring ovulation would occur following every oestrus. Early in the validation of the LH assay we discovered that unfrozen urine samples were essential, as quantifiable decreases in LH concentration were measured with each freeze-thaw cycle that the sample experienced. Following this discovery, all urine samples collected from the female were aliquoted into two vials, with one kept at refrigerator temperature to use in the LH EIA. During most of the oestrous cycles, the female would urinate up to 8 times during a $24 \mathrm{~h}$ period, but around oestrus, when an $\mathrm{LH}$ surge would be expected, the female urinated with intense frequency (up to 30 times during a $24 \mathrm{~h}$ period). Additionally, it appeared that the LH surges of the Indian rhinoceros were cleared through the kidneys and into the urine rather rapidly. Therefore, long term monitoring of urinary LH during all oestrous cycles was not deemed to be logistically feasible because all urine excreted would have had to be collected and analysed. However, the establishment 
and use of the LH assay was essential to document the female's response to GnRH challenges.

Results from the two GnRH trials indicate that administration of $500 \mu \mathrm{g} \mathrm{GnRH}$ on the day of peak oestrus does stimulate LH release from the pituitary of the female Indian rhinoceros that can be measured in the urine approximately $2 \mathrm{~h}$ following injection. However, $\mathrm{GnRH}$ did not induce ovulation. Although the oestrous cycle associated with $\mathrm{GnRH}$ Trial no. 1 was ovulatory, ovulation did not appear to be due to GnRH administration. The oestrous cycle associated with Trial no. 1 had two separate occasions of behavioural oestrus and administration of $\mathrm{GnRH}$ during the first oestrus did not advance ovulation and prevent the occurrence of a second behavioural oestrus. Because an LH surge followed the GnRH injection, it is unlikely that failure to induce ovulation was due to differences in the recognition, binding and response of the Indian rhinoceros $\mathrm{GnRH}$ receptors to the form of $\mathrm{GnRH}$ that was administered. More likely, the female failed to ovulate due to insufficient maturation of the preovulatory follicle at the time of the first behavioural oestrus. Despite the $\mathrm{GnRH}$-induced LH surge during the first oestrus, pituitary stores were not depleted as an endogenous LH surge occurred several days later, followed by ovulation. Because a $500 \mu \mathrm{g} \mathrm{GnRH}$ dose tested in Trial no. 1 resulted in an LH surge, the same dosage was tested during a second trial to confirm consistency of the elicited response. Results from Trial no. 2 confirmed that an LH surge occurs in response to this treatment and can be detected in the urine $\sim 2 \mathrm{~h}$ post-injection. In fact, $\mathrm{LH}$ concentrations appeared slightly higher in this second trial. Even so, the cycle was anovulatory, suggesting that a single GnRH injection will not induce ovulation of a follicle destined to be anovulatory. This finding is consistent with those documented in the horse. Not all mares responded with ovulation of a dominant follicle following administration of $\mathrm{GnRH}$ during the anovulatory season (Ginther \& Bergfelt 1990) and the majority of attempts to induce ovulation were associated with the formation of a luteinized anovulatory follicle (McCue 1998, McCue \& Squires 2002).

The reproductive physiology of the female Indian rhinoceros appears to be uniquely species-specific in many ways and by no means simple to comprehend. Results from the present study help elucidate some of this species' reproductive characteristics largely due to the integration of ultrasonography with the more traditional methods used to study reproductive function. Through the use of ultrasonography, we were able to document the unique follicular dynamics associated with the oestrous cycle of the female Indian rhinoceros. In addition, we established patterns of follicular growth, timing of ovulation in relation to oestrus, hormonal measures that may predict ovulation in this species, and documentation of infertile cycles that would otherwise not have been apparent through traditional measures. These results provide a more complete and detailed understanding of the reproductive physiology of the Indian rhinoceros that may aid in the development of assisted reproductive technologies and/or provide better methods for accurately timing natural breeding attempts.

\section{Acknowledgements}

This research was funded, in part, by a grant from the Morris Animal Foundation (D03ZO-58) and the Center for Conservation and Research of Endangered Wildlife's Rowe and Beth Hoffman Post-doctoral Fellowship. The authors thank the rhino keepers and veterinary staff of the Cincinnati Zoo and Botanical Garden for their dedication to the animals and this project. Of these people, special thanks are extended to Dr Mark Campbell for his assistance during the GnRH trials, team leader and head keeper Paul Reinhardt and rhino keepers Libby Flaherty, Salomon Noble and Steve Yelverton for their remarkable proficiency at conditioning the female rhinos used in the study for ultrasonography, and their conscientious collection of urine samples and behavioural data. Additionally, we thank Helen Bateman, MSc at CREW at the Cincinnati Zoo and Botanical Garden, Molly Haffey, DVM and Cynthia Johnson, $\mathrm{PhD}$, for their assistance during this project and Christopher DeChant, MSc, for his assistance in setting up the LH assay.

\section{References}

Berkeley EV, Kirkpatrick JF, Schaffer NE, Bryant WM \& Threlfall WR 1997 Serum and fecal steroid analysis of ovulation, pregnancy and parturition in the black rhinoceros (Diceros bicornis). Zoo Biology $16121-132$.

Carnedale EM 1998 Folliculogenesis and ovulation. In Equine Diagnostic Ultrasonography, pp 201-210. Eds NW Rantanen \& AO McKinnon. Baltimore: Williams and Wilkens.

Cassar CA, Dow MP, Pursley JR \& Smith GW 2002 Effect of the preovulatory LH surge on bovine follicular progesterone receptor mRNA expression. Domestic Animal Endocrinology 22 179-187.

Davis ME 1946 The clinical use of oral basal temperatures. Journal of the American Medical Association 130 929-932.

Dinerstein E 2003 The Return of the Unicorns - The Natural History and Conservation of the Greater One-Horned Rhinoceros, pp 18-24. New York: Columbia University Press.

Foose TJ \& Van Strien N 1997 Asian Rhinos: Status Survey and Conservation Action Plan, pp 5-20. Switzerland: IUCN.

Garnier JN, Holt WV \& Watson PF 2002 Non-invasive assessment of oestrous cycles and evaluation of reproductive seasonality in the female wild black rhinoceros (Diceros bicornis minor). Reproduction 123 877-889.

Ginther OJ 1995 Follicles. In Ultrasonic Imaging and Animal Reproduction: Horses Book 2, pp 43-72. Wisconsin: Equiservices Publishing.

Ginther OJ \& Bergfelt DR 1990 Effect of GnRH treatment during the anovulatory season on multiple ovulation rate and on follicular development during the ensuing pregnancy in mares. Journal of Reproduction and Fertility 88 119-126.

Graham LH, Bolling J, Miller G, Pratt-Hawkes N \& Joseph S 2002 Enzyme-immunoassay for the measurement of luteinizing hormone in the serum of African elephants (Loxodonta africana). Technical Report. Zoo Biology 21 403-408.

Hafez ESE 1993 Reproductive behavior. In Reproduction in Farm Animals, 6th edn, pp 237-257. Pennsylvania: Lea \& Febiger.

Hermes R, Olson D, Goritz F, Brown JL, Schmitt DL, Hagan D, Peterson JS, Guido F \& Hildebrandt TB 2000 Ultrasonography of 
the estrous cycle in female African elephants (Loxodonta africana). Zoo Biology 19 369-382.

Hildebrandt TB, Goritz F, Pratt NC, Brown JL, Montali RJ, Schmitt DL, Fritsch G \& Hermes R 2000 Ultrasonography of the urogenital tract in elephants (Loxodonta africana and Elephas maximus): an important tool for assessing female reproductive function. Zoo Biology 19 321-332.

Hlavacek G, Zschokke S \& Guldenschuh G 2002 In International Studbook for the Greater One-Horned or Indian Rhinoceros, Rhinoceros unicornis, pp 6-26. Switzerland: Zoo Basel.

Hodges JK \& Hindle JE 1988 Comparative aspects of urinary hormone excretion in the rhinoceroses: implications for reproductive assessment. In Proceedings of the 5th World Conference on Breeding Endangered Species in Captivity, pp 83-91. Eds BL Dresser, RW Reece \& EJ Maruska. Cincinnati: Cincinnati Zoo and Botanical Garden.

Hodges JK \& Green DI 1989 The development of an enzyme-immunoassay for urinary pregnanediol-3-glucuronide and its application to reproductive assessment in exotic mammals. Journal of Zoology 219 89-99.

Irvine CH, Alexander SL \& McKinnon AO 2000 Reproductive hormone profiles in mares during the autumn transition as determined by collection of jugular blood at 6-hour intervals throughout ovulatory and anovulatory cycles. Journal of Reproduction and Fertility $118101-109$.

Jo M, Komar CM \& Fortune JE 2002 Gonadotropin surge induces two separate increases in messenger RNA for progesterone receptor in bovine preovulatory follicles. Biology of Reproduction $\mathbf{6 7}$ 1981-1988.

Kapustin N, Critser JK, Olson D \& Malven PV 1996 Nonluteal estrous cycles of 3 -week duration are initiated by anovulatory luteinizing hormone peaks in African elephants. Biology of Reproduction 55 1147-1154.

Kasman LH, Ramsay EC \& Lasley BL 1986 Urinary steroid evaluations to monitor ovarian function in exotic ungulates: III. Estrone sulfate and pregnanediol-3-glucuronide excretion in the Indian rhinoceros (Rhinoceros unicornis). Zoo Biology 5 355-361.

Kassam AAH \& Lasley BL 1981 Estrogen excretory patterns in the Indian rhinoceros (Rhinoceros unicornis) determined by simplified urinary analysis. American Journal of Veterinary Research 42 251-255.

Khan MKM, Roth TL \& Foose TJ 1999 In situ and ex situ efforts to save the Sumatran rhinoceros (Dicerorhinus sumatrensis). In Proceedings of the 7th World Conference on Breeding Endangered Species, pp 163-174. Eds TL Roth, WF Swanson \& LK Blattman. Cincinnati: Cincinnati Zoo and Botanical Garden.

McCue PM 1998 Review of ovarian abnormalities in the mare. Proceedings of the American Association of Equine Practitioners 44 125-133.

McCue PM \& Squires EL 2002 Persistent anovulatory follicles in the mare. Theriogenology 58 541-543.

McKinnon AO 1998 Ovarian abnormalities. In Equine Diagnostic Ultrasonography, pp 233-241. Eds NM Rantanen \& AO McKinnon. Baltimore: Williams \& Wilkins.

Munro CJ, Stabenfeldt GH, Cragun JR, Addiego LA, Overstreet JW \& Lasley BL 1991 Relationship of serum estradiol and progesterone concentrations to the excretion profiles of their major urinary metabolites as measured by enzyme immunoassay and radioimmunoassay. Clinical Chemistry 37 838-844.

Patton ML, Swaisgood RR, Czekala NM, White AM, Fetter GA, Montagne JP, Rieches RG \& Lance VA 1999 Reproductive cycle length and pregnancy in the Southern White rhinoceros (Ceratotherium simum simum) as determined by fecal pregnane analysis and observations of mating behavior. Zoo Biology 18 $111-127$.
Radcliffe RW, Czekala NM \& Osofsky SA 1997 Combined serial ultrasonography and faecal progestin analysis for reproductive evaluation of the female white rhinoceros (Ceratotherium simum simum): preliminary results. Zoo Biology 16 445-456.

Radcliffe RW, Eyres AI, Patton ML, Czekala NM \& Emslie RH 2001 Ultrasonographic characterization of ovarian events and fetal gestational parameters in two southern Black rhinoceros (Diceros bicornis minor) and correlation to fecal progesterone. Theriogenology 55 1033-1049.

Ramsay EC, Kasman LH \& Lasley BL 1987 Urinary steroid evaluations to monitor ovarian function in exotic ungulates: V. Estrogen and pregnanediol-3-glucuronide excretion in the black rhinoceros (Diceros bicornis). Zoo Biology 6 275-282.

Roth TL \& Brown JL 1999 Is there any rhyme or reason to rhino reproduction? A summary of the reproductive characteristics, species-specificities and challenges for the future. In Proceedings of the American Association of Zoo Veterinarians Annual Conference, pp 97-99. Ed. CK Baer. Columbus, OH: Columbus Zoo.

Roth TL, O'Brien JK, McRae MA, Bellem AC, Romo SJ, Kroll JL \& Brown JL 2001 Ultrasound and endocrine evaluation of the ovarian cycle and early pregnancy in the Sumatran rhinoceros Dicerorhinus sumatrensis. Reproduction 121 139-149.

Roth TL, Bateman HL, Kroll JL, Steinetz BG \& Reinhart PR 2004 Endocrine and ultrasonographic characterization of a successful pregnancy in a Sumatran rhinoceros (Dicerorhinus sumatransis) supplemented with a synthetic progestin. Zoo Biology 23 219-238.

Schwarzenberger F, Francke R \& Goltenboth R 1993 Concentrations of faecal immunoreactive progestagen metabolites during the oestrous cycle and pregnancy in the black rhinoceros (Diceros bicornis michaeli). Journal of Reproduction and Fertility 98 285-291.

Schwarzenberger F, Walzer C, Tomasova K, Vahala J, Meister J, Goodrowe KL, Zima J, Straub G \& Lynch M 1998 Fecal progesterone metabolite analysis for non-invasive monitoring of reproductive function in the white rhinoceros (Ceratotherium simum). Animal Reproduction Science 53 173-190.

Schwarzenberger F, Rietschel W, Vahala J, Holeckova D, Thomas P, Maltzan J, Baumgartner K \& Schaftenaar W 2000 Fecal progesterone, estrogen, and androgen metabolites for noninvasive monitoring of reproductive function in the female Indian rhinoceros, Rhinoceros unicornis. General and Comparative Endocrinology 119 300-307.

Stouffer RL 2002 Pre-ovulatory events in the rhesus monkey follicle during ovulation induction. Reproductive Biomedicine Online 4 (Suppl 3) 1-4.

Watson ED, Thomassen R, Steele M, Heald M, Leask R, Groome NP \& Riley SC 2002 Concentrations of inhibin, progesterone and oestradiol in fluid from the dominant and subordinate follicles from mares during spring transition and the breeding season. Animal Reproduction Science 74 55-67.

Zalanyi S 2001 Progesterone and ovulation. European Journal of Obstetrics and Gynecology and Reproductive Biology 98 $152-159$.

Zschokke S, Suder P \& Baur B 1998 Past and future breeding of the Indian rhinoceros in captivity. International Zoo News $\mathbf{4 5}$ 261-276.

Received 21 May 2004

First decision 30 June 2004

Revision manuscript received 3 August 2004

Accepted 13 August 2004 